\title{
PENINGKATAN KUALITAS PUBLIKASI ILMIAH DAN PENELITIAN BAGI GURU SLTA DENGAN PEMANFAATAN SOFTWARE REFERENSI
}

\author{
Afdhil Hafid*, Harun Mukhtar, Regiolina Hayami, Yulia Fatma, Mitra Unik, \\ Yoze Rizki, Hasanuddin \\ Prodi Teknik Informatika, Fakultas Ilmu Komputer \\ Universitas Muhammadiyah Riau \\ email: afdhilhafid@umri.ac.id
}

\begin{abstract}
Republic of Indonesia Law No. 14 of 2005 describes teachers as professional educators with the main task of educating, teaching, guiding, directing, training, evaluating, and evaluating students in the formal education listed. The teacher has an important role in planning and implementing the learning process, so as to obtain opportunities to improve competence. One of the activities that must be carried out by teachers in developing their competence as teachers is scientific publications, which are listed in Article 11 of the Minister of PAN \& RB Regulation No. 16 of 2009 concerning teacher functional positions. In designing scientific publications there are stages and methods that are different from other papers. The research work comes from the research activities carried out so that it can be a reference in the follow-up of educational activities. The existence of information technology devices makes it easy for teachers to carry out research activities to publish them. The more research carried out at this time is not necessarily comparable with the quality of research. The demand to fulfill good and correct reference criteria is a challenge for teachers in the stages of reviewing and following up on publications.

This service activity provides other insights into better article writing and reference techniques using computer-assisted devices. Problems with the obstacles faced so far by the teacher in writing are expected to be solved so that joint efforts in creating an environment of professionalism in education can be realized.
\end{abstract}

Keywords: Scientific, Research, Publication, Reference, Software.

\section{Abstrak}

UU RI No 14 Tahun 2005 menjelaskan mengenai guru sebagai pendidik profesional dengan tugas utama mendidik, mengajar, membimbing, mengarahkan, melatih, menilai, dan mengevaluasi peserta didik pada pendidikan formal yang tercantum. Guru memiliki peran penting dalam perecanaan dan pelaksanaan proses pembelajaran, sehingga memperoleh kesempataan untuk meningkatkan kompetensi. Salah satu kegiatan yang wajib dilakukan guru dalam mengembangkan kompetensinya sebagai guru adalah publikasi ilmiah, yang tercantum dalam Pasal 11 Peraturan Menteri PAN \& RB No 16 tahun 2009 tentang jabatan fungsional guru. Pada perancangan publikasi ilmiah terdapat tahapan dan metode yang berbeda dengan karya tulis lainnya. Karya penelitian berasal dari kegiatan penelitian yang dilakukan sehingga dapat menjadi acuan dalam tindak lanjut kegiatan pendidikan. Keberadaan perangkat teknologi informasi memudahkan guru dalam melakukan kegiatan penelitian hingga mempublikasikannya. Semakin banyak penelitian yang dilakukan saat ini belum tentu sebanding dengan kualitas peneleitian. Tuntutan untuk memenuhi kriteria referensi yang baik dan benar menjadi tantangan tersendiri bagi guru dalam tahap peninjauan dan penindaklanjutan publikasi.

Kegiatan pengabdian ini memberikan wawasan lain dalam teknik penulisan artikel dan penyusunan referensi secara lebih baik menggunakan perangkat berbantu komputer. Permasalahan terhadap kendala yang dihadapi selama ini oleh guru dalam menulis diharapkan dapat terpecahkan sehingga upaya bersama dalam menciptakan lingkungan profesionalisme 
ISSN : 2550-0198

dalam pendidikan dapat terwujud.

Kata kunci: Ilmiah, Penelitian, Publikasi, Referensi, Software.

\section{PENDAHULUAN}

Menurut

Undang-Undang

Republik Indonesia Nomor 14 Tahun 2005, guru adalah pendidik profesional dengan tugas utama mendidik, mengajar, membimbing, mengarahkan, melatih, menilai, dan mengevaluasi peserta didik pada pendidikan anak usia dini jalur pendidikan formal, pendidikan dasar, dan pendidikan menengah. Pada peningkatan dan pengembangan kualifikasi akademik dan kompetensi secara berkelanjutan sejalan dengan perkembangan ilmu pengetahuan, teknologi, dan seni (UU NO. 14 Tahun 2005, 1999) (Hafiar et al., 2015) (Setiawati, Pascasarjana and Yogyakarta, 2018).

Perkembangan informasi dan teknologi sangat penting sejalan dengan kebutuhan dan persaingan dalam upaya membuat, mengolah, dan pemanfaatan informasi sebagai sebuah komoditas yang bernilai. Keberadaan lingkungan pendidikan secara signifikan mempercepat kemajuan teknologi dan perkembangan teknologi informasi. Lingkungan pendidikan memiliki peran dan tuntutan untuk mengembangkan setiap basis ilmu pengetahuan. Hal inilah yang menjadi dasar pendidik sebagai aktor dalam pengembangan pengetahuan yang tidak dapat dilakukan tanpa adanya riset berkelanjutan.

Pada lingkup pendidikan formal berdasar Peraturan Pemerintah No. 19 Tahun 2005 tentang Standar Nasional Pendidikan, diterbitkan Peraturan Menteri Pendidikan Nasional Republik Indonesia Nomor 16 Tahun 2007 Tentang Standar Kualifikasi Akademik dan Kompetensi Guru. Dalam peraturan tersebut, dijelaskan bahwa Standar kompetensi guru dikembangkan secara utuh dari empat kompetensi utama, yaitu: kompetensi pedagogik, kompetensi kepribadian, kompetensi sosial. kompetensi profesional.

Pengembangan kompetensi guru yang dilaksanakan sesuai dengan kebutuhan, bertahap, dan berkelanjutan untuk meningkatkan profesionalitasnya. PKB bagi guru mencakup tiga kegiatan yaitu: (1) pengembangan diri; (2) publikasi ilmiah; dan (3) karya inovatif. Tujuan umum PKB adalah untuk meningkatkan kualitas layanan pendidikan di sekolah dalam rangka meningkatkan mutu pendidikan. PKB semakin relevan dengan diterapkannya Peraturan Menteri Pendayagunaan Aparatur Negara dan Reformasi Birokrasi (Menpan \& RB) Nomor 16 Tahun 2009 tentang Jabatan Fungsional Guru dan Angka Kreditnya. Dalam hal ini setiap guru dituntut untuk menyusun rencana pengembangan diri melalui program PKB Berdasar pada Peraturan Menteri PAN \& RB tersebut di atas maka jelas bahwa guru dengan jenjang apapun diwajibkan untuk melaksanakan publikasi ilmiah, sehingga tidak ada celah sedikitpun bagi guru yang akan mengembangkan karirnya untu mengelak dari kewajiban melakukan publikasi ilmiah (Masduki and Kholid, 2017) (Krismanto, 2016) (Widagdo, 2018).

Pada tahap penulisan publikasi ilmiah, guru melakukan tahap perancangan penelitian, melakukan peninjauan, analisis, mengevaluasi dan proyeksi terhadap hasil penelitian. Guru sebagai pendidik profesional dituntut untuk mampu melakukan tahap perancangan hingga proyeksi disamping melakukan tugas pokok dan fungsi dalam lingkungan pendidikan. 
Keterbatasan pengetahuan dan sumber informasi yang tersedia pada lingkungan pendidikan formal menyebabkan sebagian guru kurang bisa maksimal dalam sisi pengembangan pendidikan terutama penelitian dan publikasi ilmiah. Ada banyak upaya yang dilakukan oleh sekolah untuk meningkatkan kapasitas guru pada sisi ini sebagai bagian dari kegiatan penunjang. Beberapa hal yang dapat dilakukan dalam meningkatkan kompetensi antara lain dengan memfasilitasi kegiatan-kegiatan pelatihan/diklat, workshop, dan penataran.

Program Studi Teknik Informatika Universitas Muhammadiyah Riau sebagai bagian dari lingkungan pendidikan tinggi di Provinsi Riau bertanggungjawab dalam pengembangan pendidikan dalam bentuk kegiatan pengabdian. Salah satu upaya tersebut diantaranya secara konsisten melakukan upgrading pada lingkungan pendidikan menengah atas. Berdasarkan permasalahan di atas maka dalam upaya berbagi informasi dan teknik dalam penulisan karya ilmiah dengan pemanfaatan perangkat teknologi informasi (sotware) referensi menggunakan Mendeley dalam peningkatan kualitas publikasi/karya ilmiah.

Mendeley merupakan software manajemen referensi dalam mengorganisir penelitian, dan jaringan sosial akademis yang bermanfaat dalam berkolaborasi dengan peneliti lain secara online dan menemukan publikasi penelitian. Sebagai database referensi, file referensi seperti buku atau artikel dari jurnal dalam bentuk PDF bisa disimpan dan diberi keterangan yang tepat untuk membantu mempermudah pencarian. File-file PDF yang disimpan juga bisa dibuka, dibaca, dan diberi catatan- catatan dengan sticky notes atau highlight. Tulisan yang dibuat dengan
Microsoft Word, OpenOffice atau LaTex bisa dihubungkan dengan software Mendeley sehingga sitasi dan daftar referensi (bibliography) bisa disusun secara otomatis (Trisasti, 2016)(Sejati, 2012)(Widyastuti, 2016).

Mendeley dapat dihubungkan dengan software manajemen referensi lain yang biasa digunakan seperti EndNote, Papers dan Zotero. Pemanfaatan software Mendeley dengan melakukan sinkronisasi, otomasi dalam melakukan sitasi dan manajemen referensi, sehingga buku, jurnal, dan karya ilmiah yang menjadu referensi tulisan dapat terdokumentasi dengan baik (Trisasti, 2016) (Eko and Widianto, 2016).

\section{METODE PELAKSANAAN}

Sejalan dengan permasalahan yang telah diuraikan, maka kerangka pelaksanaan dan teknik pencapaian solusi yang ditawarkan dalam kegiatan pengabdian ini antara lain adalah dengan memberikan seminar dan workshop/pelatihan. Sosialisasi metode penelitian dan workshop diberikan kepada seluruh guru-guru yang ada di SMK Muhammadiyah 3 Pekanbaru. Kegiatan ini disusun secara sistematis dari tahap perencanaan hingga prosedur proyeksi hasil penelitian yaitu dalam bentuk laporan penelitian, atikel ilmiah dan publikasi.

Diharapkan setiap guru dapat menggunakan/memanfaatkan perangkat berbantu komputer dalam tahap perencanaan hingga proyeksi hasil berupa publikasi ilmiah. Kegiatan pengabdian yang dilaksanakan di SMK Muhammadiyah 3 Pekanbaru pada 1920 September 2018. Peserta yang terlibat dalam kegiatan ini terdiri dari 34 guru yang berasal dari berbagai disiplin ilmu yang ada di SMK Muhammadiyah 3 Pekanbaru.

Pelaksanaan kegiatan pengabdian kepada masyarakat di SMK 
Muhammadiyah 3 Pekanbaru meliputi persiapan, pelaksanaan pengabdian dan evaluasi. Kegiatan tersebut dapat dilihat pada tabel berikut ini :

Tabel 1. Tahapan Pelaksanaan Kegiatan

\begin{tabular}{|c|c|c|}
\hline No & Tahapan & Kegiatan \\
\hline 1 & Persiapan & 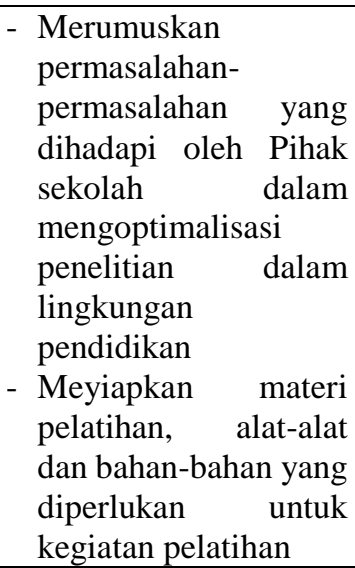 \\
\hline 2 & Pelaksanaan & $\begin{array}{l}\text { - Penyampaian Materi } \\
\text { Metode Penelitian } \\
\text { - Workshop } \\
\text { penggunaan } \\
\text { Mendeley }\end{array}$ \\
\hline 3 & Evaluasi & $\begin{array}{lr}\text { - Evaluasi } & \text { hasil } \\
\text { untuk kerja } & \text { mengetahui } \\
\text { kendala } & \text { selama } \\
\text { pelatihan } & \end{array}$ \\
\hline
\end{tabular}

\section{HASIL DAN PEMBAHASAN}

Kegiatan seminar dan pelatihan yang dilaksanakan pada 19-20 September 2018 di SMK Muhammadiyah 3, Pekanbaru. Pelatihan diikuti oleh 34 peserta yang terdiri dari perangkat sekolah, guru kelas dan guru mata pelajaran di SMK Muhammadiyah 3 Pekanbaru. Metode meliputi: ceramah, praktek, diskusi dan tanya jawab.

1. Ceramah dan diskusi.

Kegiatan sosialisasi metode penelitian dilaksanakan pada hari Kamis, 19 September 2019. Sosialisasi teknik metode penelitian disampaikan oleh pemateri meliputi tahapan yang dilakukan dari mulai perencanaan, pelaksanaan hingga proyeksi hasil, kriteria karya tulis yang tergolong ke dalam penelitian. Kemudian materi juga meliputi halhal yang fundamental terkait dengan perbedaan publikasi penelitian dengan karya tulis lain.

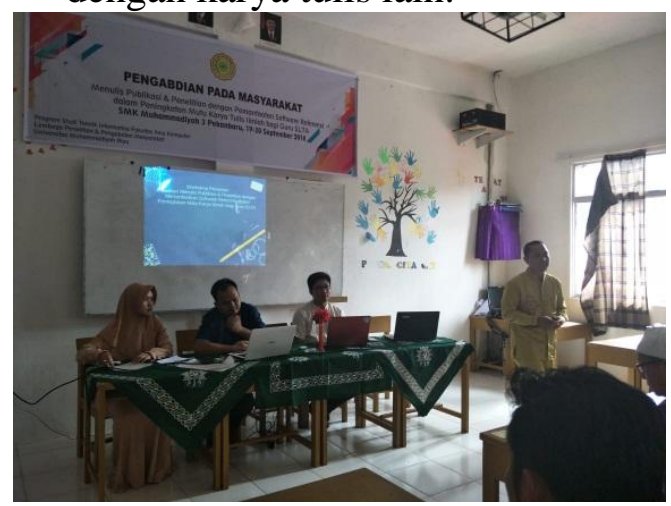

Gambar 1. Materi 1 - menulis artikel ilmiah dan metode penelitian

2. Workshop

Workshop dan pendampingan penulisan artikel ilmiah, selanjutnya menggunakan software referensi Mendeley yang digunakan dalam pencarian, penyusunan artikel rujukan serta teknik pengutipan. Tahap pendampingan penulisan artikel ilmiah dimulai dari sosialisasi prosedur memulai dan penggunaan aplikasi referensi Mendeley. Setelah pelatihan guru diberi kesempatan untuk mulai menulis rancangan artikel ilmiah.



Gambar 2. Materi 2-workshop teknik penulisan artikel ilmiah menggunakan Software Mendeley

Tindakan dalam kegiatan ini berupa implementasi program. Kegiatankegiatan yang dilakukan dalam 
implementasi program adalah sebagai berikut.

1. Memberikan pengenalan kepada guru-guru terkait berbagai macam berntuk penelitian yang dapat dilakukan oleh guru di tingkat pendidikan menengah atas.

2. Meningkatkan pengetahuan dan keterampilan para guru tentang pembuatan laporan/publikasi penelitian dan mensosialisasikan keuntungan penggunaan aplikasi referensi dalam upaya peningkatan kualitas publikasi ilmiah dan prosedural

3. Mendemonstrasikan penggunaan aplikasi referensi Mendeley dalam tahapan peningkatan kuantitas dan kualitas publikasi yang ada di sekolah.

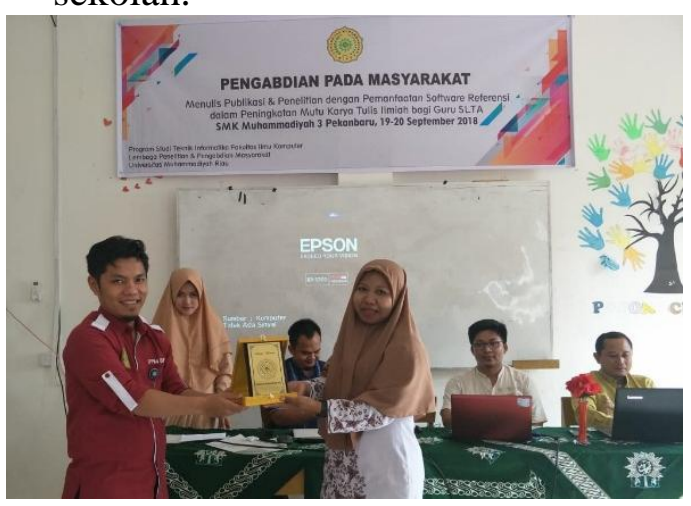

Gambar 3. Penyerahan kenang-kenangan dari Prodi Teknik Informatika kepada pihak SMK Muhammadiyah 3 Pekanbaru

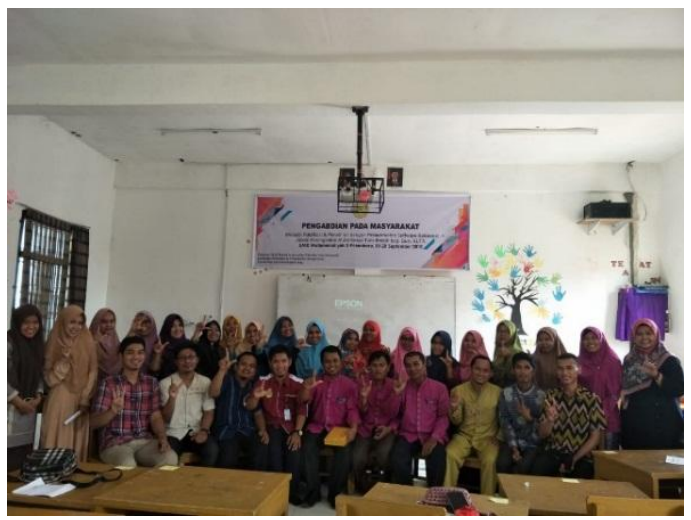

Gambar 4. Foto bersama peserta setelah kegiatan seminar \& workshop

Setelah kegiatan pengabdian ada beberapa evaluasi dari yang telah dilakukan. Metode evaluasi yang dilakukan dengan mengamati hasil pelatihan yang didapat, yaitu peserta sangat antusias dengan jumlah peserta yang melebihi target awal 25 orang menajadi 34 orang. Kemudian peserta terlibat diskusi aktif dari kegiatan workshop dengan teknik penulisan publikasi menggunakann software yang masih baru bagi peserta. Disamping itu, setelah selesainuya kegiatan, para peserta mengharapkan agar kegiatan ini dapat berlanjut terutama jika materi yang sama untuk jangka waktu lebih panjang dan dengan materi yang berbeda terkait dengan upaya mendukung proses pembelajaran.

\section{SIMPULAN}

Berdasarkan kegiatan pengabdian masyarakat yang telah dilakukan di SMK Muhammadiyah 3 Pekanbaru, hasil yang dicapai adalah sebagai berikut:

a. Bertambahnya pengetahuan guruguru SMK Muhammadiyah 3 Pekanbaru tentang teknik melakukan penelitian, menulis publikasi ilmiah dan proyeksi hasil penelitian yang dalam upaya evaluasi dan pengembangan pendidikan.

b. Bertambahnya wawasan dalam teknis menulis publikasi dengan menggunakan software referensi Mendeley.

Dari hasil pelaksanaan kegiatan pengabdian masyarakat dapat disampaikan beberapa saran berikut :

a. Diharapakan agar para guru selalu mengembangkan kemampuan dan juga pemahamannya terkait prosedur dan teknik dalam melakukan penelitian dan menyusun laporan penelitian dan karya tulis ilmiah. Hal ini bermanfaat dalam peningkatan profesionalisme dan kapabilitas dalam pengembangan dispilin ilmu melalui lebih banyak melakukan penelitian dan publikasi ilmiah.. 
b. Guru diharapakan pada tahapan berikutnya tidak menghadapi kendala terkait dengan pelaksanaan penelitian dan publikasi karya tulis/artikel ilmiah, sehingga publikasi di sekolah dapat meningkat secara kuantitas dan kualitas

\section{UCAPAN TERIMAKASIH}

Ucapan terimakasih disampaikan kepada: (1) Lembaga Penelitian dan Pengabdian Masyarakat (LPPM) Universitas Muhammadiyah Riau (UMRI) yang telah memberikan dukungan dalam pelaksanaan kegiatan pengabdian secara materi dan administrasi. (2) SMK Muhammadiyah 3 Pekanbaru yang telah memfasilitasi kegiatan ini. (3) Dekan beserta jajaran di Fakultas Ilmu Komputer UMRI (4) Segenap tim pelaksana kegiatan, dan (5) Semua pihak yang telah membantu terlaksananya kegiatan ini.

\section{DAFTAR PUSTAKA}

[1] Eko, O. and Widianto, D. (2016) 'Tentang Mendeley', (April), pp. 25-29.

[2] Hafiar, H. et al. (2015) 'Peningkatan Pendidikan Dan Pengembangan Kompetensi Guru SMA Negeri 1 Katapang Melalui Partisipasi Dalam Publikasi Akademis Di Media Massa', Jurnal Dharmakarya, 4(2), pp. 88-92.

[3] Krismanto, W. (2016) 'Publikasi ilmiah sebagai wujud profesionalisme guru 1', pp. 1-10.

[4] Masduki and Kholid, M. N. (2017) 'Pengembangan Kemampuan Penelitian dan Penulisan Karya Ilmiah Guru Matematika SMA/ SMK Muhammadiyah Di Klaten dan Sukoharjo', Warta LPM, 20(2), pp. 115-122.

[5] Sejati, A. W. (2012) 'Manajemen referensi pustaka dengan mendeley desktop', Medice, IV, p. 334.

[6] Setiawati, E., Pascasarjana, P. I. P.
S. and Yogyakarta, U. P. (2018) 'Workshop Penyusunan Proposal Penelitian Tindakan Kelas dan Artikel Ilmiah pada Guru Bk SMA / MA di Kabupaten Bantul', 1(1), pp. 34-44.

[7] Soni et al., "Optimalisasi Pemanfaatan Google Classroom Sebagai Media Optimalisasi Pemanfaatan Google Classroom Sebagai Media Pembelajaran Di Smk Negeri 1 Bangkinang," J. Pengabdi. Untuk Mu NegeRI, vol. 2, no. Mei 2018, pp. 17-20, 2018.

[8] Trisasti, L. (2016) 'Panduan Penggunaan Software Manajemen Referensi Mendeley', pp. 1-16.

[9] UU NO. 14 Tahun 2005 (1999) 'Undang Undang No. 14 Tahun 2005', http://sumberdaya.ristekdikti.go.id. Available at: http://jdih.esdm.go.id/peraturan/Pe rpres No. 78 Thn 2013.pdf.

[10] Widagdo, A. S. (2018) 'Pelatihan Penulisan Artikel Ilmiah Abstrak', 3(3), pp. 25-29.

[11] Widyastuti, P. (2016) 'Mengelola Referensi Artikel Ilmiah Menggunakan Aplikasi Mendeley.' 